Cite this: Phys. Chem. Chem. Phys., 2014, 16, 11965

Received 5th December 2013, Accepted 28th February 2014

DOI: $10.1039 / c 3 c p 55125 c$

www.rsc.org/pccp

\title{
Water oxidation by manganese oxides formed from tetranuclear precursor complexes: the influence of phosphate on structure and activity $\dagger$
}

\author{
Denys Shevchenko, ${ }^{a}$ Magnus F. Anderlund, ${ }^{\mathrm{b}}$ Stenbjörn Styring, ${ }^{\mathrm{b}}$ Holger Dau, \\ Ivelina Zaharieva*c and Anders Thapper ${ }^{* b}$
}

\begin{abstract}
Two types of manganese oxides have been prepared by hydrolysis of tetranuclear $\mathrm{Mn}(\mathrm{III})$ complexes in the presence or absence of phosphate ions. The oxides have been characterized structurally using X-ray absorption spectroscopy and functionally by $\mathrm{O}_{2}$ evolution measurements. The structures of the oxides prepared in the absence of phosphate are dominated by di- $\mu$-oxo bridged manganese ions that form layers with limited long-range order, consisting of edge-sharing $\mathrm{MnO}_{6}$ octahedra. The average manganese oxidation state is +3.5 . The structure of these oxides is closely related to other manganese oxides reported as water oxidation catalysts. They show high oxygen evolution activity in a light-driven system containing $\left[\mathrm{Ru}(\mathrm{bpy})_{3}\right]^{2+}$ and $\mathrm{S}_{2} \mathrm{O}_{8}{ }^{2-}$ at $\mathrm{pH}$ 7. In contrast, the oxides formed by hydrolysis in the presence of phosphate ions contain almost no di- $\mu$-oxo bridged manganese ions. Instead the phosphate groups are acting as bridges between the manganese ions. The average oxidation state of manganese ions is +3 . This type of oxide has much lower water oxidation activity in the light-driven system. Correlations between different structural motifs and the function as a water oxidation catalyst are discussed and the lower activity in the phosphate containing oxide is linked to the absence of protonable di- $\mu$-oxo bridges.
\end{abstract}

\section{Introduction}

Today fossil fuels are used to produce a major fraction of the energy needed for our society. Enormous efforts are being devoted to developing strategies to break this dependency and to produce large amounts of energy from renewable resources to meet the rising energy demands. The influx of solar energy to Earth is clearly large enough to allow for energy production on a global scale but efficient energy conversion and storage will be essential to render the full potential of solar energy accessible. ${ }^{1,2}$

One attractive possibility is to store the solar energy in chemical bonds of molecules. This means that a fuel is produced. To be conceivable on a global scale, the starting material for the fuel needs to be highly abundant. Artificial photosynthesis

\footnotetext{
${ }^{a}$ Analytical Chemistry, Department of Chemistry - Biomedical Center,

Uppsala University, P.O. Box 599, S-75124 Uppsala, Sweden

${ }^{b}$ Molecular Biomimetics, Department of Chemistry - Angström Laboratory,

Uppsala University, P.O. Box 523, S-75120 Uppsala, Sweden.

E-mail: anders.thapper@kemi.uu.se

${ }^{c}$ Freie Universität Berlin, Institut für Experimentalphysik, Arnimallee 14,

14195 Berlin, Germany. E-mail: ivelina.zaharieva@fu-berlin.de

$\dagger$ Electronic supplementary information (ESI) available: Oxygen evolution traces for chemical and light-induced water oxidation, experimental details about XAS measurements, EXAFS spectra of $2 \mathbf{b}$ and $3 \mathbf{b}$. See DOI: 10.1039/c3cp55125c
}

addresses this problem by taking inspiration from the natural photosynthetic process that uses solar energy, water and carbon dioxide to make the fuel. ${ }^{3-5}$ The first step in biological photosynthesis takes place in a photoenzyme denoted as photosystem II (PSII), where water is oxidized to oxygen, protons and electrons. ${ }^{6,7}$ The active site of biological water oxidation consists of a $\mathrm{CaMn}_{4}(\mu-\mathrm{O})_{5}$ metal-oxo core bound to specific amino-acid residues and 4 water molecules terminally coordinated to calcium and manganese; these terminal water ligands are hydrogen-bonded to further water molecules. ${ }^{8}$ In a nutshell, the biological catalyst is a binary oxide of calcium and manganese ions extensively interconnected by di- $\mu$-oxo bridging and interfaced with a cluster of water molecules.

Manganese has been used as a component in numerous attempts to develop artificial, biomimetic catalysts for water oxidation, either as manganese-containing molecular compounds ${ }^{9,10}$ or manganese-containing solid-state materials. Our work is concerned mainly with the latter catalyst type, specifically manganese oxides. As early as the late eighties, in a comprehensive study on metal oxides by Harriman and co-workers, a $\mathrm{Mn}$ (III) oxide, $\mathrm{Mn}_{2} \mathrm{O}_{3}$, was reported to work in the particle form as a water oxidation catalyst. ${ }^{11}$ To run the reaction a lightdriven system with $\left[\mathrm{Ru}(\mathrm{bpy})_{3}\right]^{2+}$ as a photosensitizer and $\mathrm{S}_{2} \mathrm{O}_{8}{ }^{2-}$ as an electron acceptor was used. Lately, manganese oxides, 
both nanostructured and amorphous, have obtained renewed interest as water oxidation catalysts. ${ }^{12-23}$ To quantify catalytic activity, light-driven systems using predominately ruthenium based photosensitizers are commonly used ${ }^{12-16}$ but also chemical oxidation using oxidants like $\mathrm{Ce}(\mathrm{Iv})^{13,14,16-18}$ or electrocatalytic systems have been employed. ${ }^{19-23}$

In 2010, Kurz and coworkers described calcium manganese oxides which were synthesized to mimic the active site $\mathrm{CaMn}_{4}(\mu-\mathrm{O})_{5}$ complex of PSII. ${ }^{13}$ The catalytic activity of specific calcium manganese oxides was clearly higher than detectable for commercial $\mathrm{Mn}_{2} \mathrm{O}_{3}$ and $\alpha-\mathrm{Mn}_{2} \mathrm{O}_{3}$. Later it was shown that the most active calcium manganese oxides had a structure composed of layers of edge-sharing $\mathrm{MnO}_{6}$ octahedra, ${ }^{14}$ similar to the structure of birnessites, ${ }^{24,25}$ a family of naturally occurring minerals. However as opposed to well-ordered birnessites, the layers of the catalytic oxide contained a large number of vacancies (defects). The calcium ions were located in the interlayer space likely involving two structural motifs: (i) calcium ions in $\mathrm{CaMn}_{3}(\mu-\mathrm{O})_{4}$ cubanes and (ii) calcium capping manganese vacancies in layers of $\mathrm{MnO}_{6}$ octahedra. ${ }^{14}$ Also other cations, like strontium and magnesium, could be used in these mixed manganese oxides and an activity scale of $\mathrm{Ca}^{2+}>\mathrm{Sr}^{2+}>\mathrm{Mg}^{2+}$ was determined. ${ }^{17}$

A manganese oxide that catalyses electrochemical water oxidation at neutral $\mathrm{pH}$ has been synthesized by means of a specific electrodeposition protocol. ${ }^{20}$ Its activity was clearly superior to previously described electrodeposited manganese oxide electrocatalysts. ${ }^{19,23}$ The key to activity was suggested to lie in controlling the oxidation state of the manganese ions and specifically in avoidance of the formation of well-ordered and thus unreactive $\mathrm{Mn}^{\mathrm{IV}} \mathrm{O}_{2}$. An average oxidation state of +3.8 for the manganese was observed in this study, identical to the oxidation state in the most active mixed manganese oxides. ${ }^{17}$ The role of $\mathrm{Mn}^{3+}$ ions for the activity of layered Mn oxides was also suggested by Takashima et al. ${ }^{26,27}$

Boppana and $\mathrm{Jiao}^{15}$ reported that $\alpha-\mathrm{MnO}_{2}$ nanotubes and $\alpha-\mathrm{MnO}_{2}$ nanowires are robust water oxidation catalysts in lightdriven reactions with $\left[\mathrm{Ru}(\mathrm{bpy})_{3}\right]^{2+}$ and $\mathrm{S}_{2} \mathrm{O}_{8}{ }^{2-}$. Najafpour ${ }^{16}$ has prepared a colloidal form of $\mathrm{MnO}_{2}$ nanoparticles and observed vastly increased water oxidation activity compared to commercial $\mathrm{Mn}_{2} \mathrm{O}_{3}$ and $\mathrm{MnO}_{2}$ in light driven reactions with $\left[\mathrm{Ru}(\mathrm{bpy})_{3}\right]^{2+}$ and $\left[\mathrm{Co}\left(\mathrm{NH}_{3}\right)_{5} \mathrm{Cl}\right]^{2-}$. In investigations of manganese complexes as potential water oxidation catalysts, the formation of catalytically active manganese oxides has been reported. Najafpour et al. ${ }^{18}$ concluded that upon treatment with highly oxidizing Ce(Iv), nanosized manganese oxide particles are formed which catalyse water oxidation. In these experiments, either solutions or microcrystalline powders of the complexes were used, or the manganese complexes were adsorbed by clay. Brimblecombe et al. ${ }^{28}$ embedded a tetranuclear manganese complex in a Nafion film and observed lightdriven water oxidation (with an external bias); a later study of Spiccia and coworkers ${ }^{29}$ suggested that the cluster dissociates in the Nafion film and that dispersed nanoparticles of a disordered mixed-valent $\mathrm{Mn}$ (III,IV) oxide are formed upon electrochemical oxidation which represent the catalytically active material. Also manganese oxides themselves can change structure under oxidising conditions. A recent study of $\mathrm{MnO}$ as a pre-catalyst for water oxidation showed that treatment with $\mathrm{Ce}(\mathrm{Iv})$ altered the structure of the oxide. ${ }^{30}$ The oxidized/corroded $\mathrm{MnO}_{x}$ formed after Ce(Iv) oxidation was active in a photochemical water oxidation experiment whereas the MnO pre-catalyst was not. XAS measurements showed that the active, corroded, structure shared structural features with other catalytically active Mn-oxides.

Herein we present the study of two types of manganese oxides prepared by hydrolysis of tetranuclear $\mathrm{Mn}$ (III) complexes; one oxide is formed in the absence of phosphate and the other in the presence of phosphate. The oxides are shown to be water oxidation catalysts in a light-driven system containing $\left[\mathrm{Ru}(\mathrm{bpy})_{3}\right]^{2+}$ and $\mathrm{S}_{2} \mathrm{O}_{8}{ }^{2-}$. X-ray absorption spectroscopy reveals that the structure of the manganese oxide is linked to the activity as a water oxidation catalyst and that the more active structure shares features with both the active site in PSII and the previously described water-oxidizing manganese oxides.

\section{Experimental section}

\section{Materials}

$\left[\mathrm{Mn}_{4}{ }_{4} \mathrm{O}_{2}(\mathrm{PhCOO})_{9}\left(\mathrm{H}_{2} \mathrm{O}\right)\right] \mathrm{N}(n-\mathrm{Bu})_{4} \quad(\mathbf{1 a}),^{31} \quad\left[\mathrm{Mn}^{\mathrm{III}}{ }_{4} \mathrm{O}_{2}(\mathrm{PhCOO})_{7^{-}}\right.$ $\left.(\mathrm{PyCOO})_{2}\right] \mathrm{N}(n-\mathrm{Bu})_{4}(\mathbf{1 b})$, and $\left[\mathrm{Ru}(\mathrm{bpy})_{3}\right]\left(\mathrm{ClO}_{4}\right)_{3} \cdot n \mathrm{H}_{2} \mathrm{O}^{32}$ were prepared as described elsewhere. The concentration of $\left[\mathrm{Ru}(\mathrm{bpy})_{3}\right]^{3+}$ was determined spectrophotometrically at $\lambda=675 \mathrm{~nm}\left(\varepsilon_{675}=\right.$ $\left.419 \mathrm{M}^{-1} \mathrm{~cm}^{-1}\right){ }^{32}$

\section{Preparation of the samples for elemental analysis, IR spectroscopy and X-ray absorption spectroscopy}

Hydrolysis of manganese complexes in the absence of phosphate buffer (2a and $2 \mathrm{~b}$ ). $250 \mathrm{mg}$ of $1 \mathrm{a}$ or $\mathbf{1 b}$ were dissolved in $15 \mathrm{ml}$ of $\mathrm{CH}_{3} \mathrm{CN}$ and $5 \mathrm{ml}$ of $\mathrm{H}_{2} \mathrm{O}$ was added. The resulting mixture was ultrasonicated for 2 minutes followed by centrifugation (14000 rpm, $5 \mathrm{~min}$ ). The supernatants were discarded and the pellets were resuspended in $15 \mathrm{ml}$ of a $\mathrm{CH}_{3} \mathrm{CN} / \mathrm{H}_{2} \mathrm{O}$ mixture $(3: 1)$ using an ultrasonic bath for $1 \mathrm{~min}$. The resuspending/centrifugation cycle was repeated 3 times, resulting in a dark brown powder that was dried under reduced pressure overnight. Elemental analysis for 2a: C, 3.97\%, H, 2.07\%, N, 0.24\%, Mn, 52.81\%. 2b: C, $2.01 \%, \mathrm{H}, 2.36 \%, \mathrm{~N}, 0.25 \%, \mathrm{Mn}, 49.84 \%$.

Hydrolysis of manganese complexes in the presence of phosphate buffer (3a and 3b). $250 \mathrm{mg}$ of $\mathbf{1 a}$ or $\mathbf{1 b}$ were dissolved in $10 \mathrm{ml}$ of $\mathrm{CH}_{3} \mathrm{CN}$ and $5 \mathrm{ml}$ of potassium phosphate buffer $(0.1 \mathrm{M}, \mathrm{pH} 7)$ was added. Ultrasonication of the resulting mixture for 2 minutes was followed by centrifugation $(14000 \mathrm{rpm}$, $5 \mathrm{~min})$. The supernatants were discarded and the pellets were resuspended in $15 \mathrm{ml}$ of the phosphate buffer. The resuspending/ centrifugation cycle was repeated 3 times resulting in a red brown powder that was dried under reduced pressure overnight. Elemental analysis for 3a: C, $0.57 \%, \mathrm{H}, 1.61 \%$, N, $<0.1 \%$, Mn, 23.71\%, P: 13.05\%. 3b: C, 0.67\%, H, 1.71\%, N, <0.1\%, Mn, 19.67\%, P: $12.79 \%$.

\section{IR spectroscopy}

Infrared spectra were recorded on a Bruker IFS 66v/S spectrometer ( $\mathrm{KBr}$ pellets). 


\section{$\mathrm{O}_{2}$ evolution experiments}

Oxygen detection of the polarographic signal from a standard Clark electrode (Hansatech Instruments), separated from the sample solution by a Teflon membrane, was recorded for the entire duration of the experiments at $0.1 \mathrm{~s}$ intervals using the CalMeter software package by Calmetric. Air saturated water solutions $\left(\left[\mathrm{O}_{2}\right]_{20^{\circ} \mathrm{C}}=276 \mu \mathrm{M}\right)$ were used for calibration of the electrode. At the beginning of each experiment the solution was thermostatted inside the double walled cell at $20{ }^{\circ} \mathrm{C}$. The gas volume above the sample solution was reduced by means of a plunger to minimize gas exchange processes. A thin channel through the plunger allowed the insertion of a Teflon tube to purge the cell with argon gas. The cell was placed on top of a magnetic stirrer to continuously stir the solution using a Teflon-coated stirrer bar. Solutions of the chemical oxidants were freshly prepared under a nitrogen atmosphere before each experiment.

Stock suspensions of the manganese oxides were prepared similarly to that described above. $1.6 \mathrm{mg}$ ( $1 \mu \mathrm{mol}$ based on complex or $4 \mu \mathrm{mol}$ based on manganese) of complex $\mathbf{1 a}$ or $\mathbf{1 b}$ were dissolved in $0.75 \mathrm{ml}$ of $\mathrm{CH}_{3} \mathrm{CN}$ and $0.25 \mathrm{ml}$ of deionized water or phosphate buffer was added. This mixture was ultrasonicated for 2 minutes followed by centrifugation (14000 rpm, $5 \mathrm{~min}$ ). The supernatant was removed and the concentration of $\mathrm{Mn}$ (II) in the supernatant was measured using EPR spectroscopy (see below). The concentration of Mn(II) was $0.77 \mathrm{mM}\left(19 \%\right.$ of $\left.\mathrm{Mn}_{\text {total }}\right)$ and $0.90 \mathrm{mM}(22 \%$ of $\left.\mathrm{Mn}_{\text {total }}\right)$ in the supernatants of $\mathbf{2 a}$ and $\mathbf{2 b}$ respectively. The supernatants of $\mathbf{3 a}$ and $\mathbf{3 b}$ contained less than $0.01 \mathrm{mM} \mathrm{Mn(II).}$

The pellets were resuspended in $1 \mathrm{ml}$ of the $\mathrm{CH}_{3} \mathrm{CN} / \mathrm{H}_{2} \mathrm{O}$ mixture $(3: 1)$ or the $\mathrm{CH}_{3} \mathrm{CN} /$ phosphate buffer mixture $(3: 1)$ using an ultrasonic bath. The resuspension/centrifugation cycle was repeated 3 times. In the end, the oxide samples were resuspended in $1 \mathrm{ml}$ deionized water in an ultrasonic bath. Concentrations of manganese in the stock suspensions were estimated by taking into account the amount of Mn(II) that was discarded when removing the supernatant during the preparation procedure.

Chemical oxidation with $\mathbf{C e}(\mathrm{Iv})$. The Clark cell was loaded with $250 \mu \mathrm{l}$ of the stock suspension of manganese oxide and $500 \mu \mathrm{l}$ of deionized water and purged with argon for $3 \mathrm{~min}$ to reach a residual concentration of molecular oxygen $\leq 10 \mu \mathrm{M}$. After an equilibration time of $2 \mathrm{~min}, 250 \mu \mathrm{l}$ of $1 \mathrm{M}$ aqueous solution of $\left(\mathrm{NH}_{4}\right)_{2} \mathrm{Ce}\left(\mathrm{NO}_{3}\right)_{6}$ was injected giving a final concentration of $0.8-1 \mathrm{mM} \mathrm{Mn}$ and $0.25 \mathrm{M}\left(\mathrm{NH}_{4}\right)_{2} \mathrm{Ce}\left(\mathrm{NO}_{3}\right)_{6}$.

Chemical oxidation with $\left[\mathrm{Ru}(\mathrm{bpy})_{3}\right]^{3+} .25 \mu \mathrm{l}$ of the stock suspension of manganese oxide was used with $500 \mu \mathrm{l}$ of aqueous potassium phosphate buffer $(0.1 \mathrm{M}, \mathrm{pH} 7)$ and $275 \mu \mathrm{l}$ of water. The cell was purged with argon as above and after 2 minutes of equilibration $200 \mu \mathrm{l}$ of $\left[\mathrm{Ru}(\mathrm{bpy})_{3}\right]^{3+}\left(0.1 \mathrm{M}\right.$ in $\mathrm{CH}_{3} \mathrm{CN} / \mathrm{H}_{2} \mathrm{O}$ mixture (3:1)) was added giving a final concentration of 80-100 $\mu \mathrm{M} \mathrm{Mn}$, $20 \mathrm{mM}\left[\mathrm{Ru}(\mathrm{bpy})_{3}\right]^{3+}$, and $50 \mathrm{mM}$ phosphate buffer.

Photochemical oxidation. $25 \mu \mathrm{l}$ of the stock suspension of manganese oxide was mixed with $500 \mu \mathrm{l}$ of $\left[\mathrm{Ru}(\mathrm{bpy})_{3}\right]^{2+}(2 \mathrm{mM})$ in $0.1 \mathrm{M}$ phosphate buffer ( $\mathrm{pH} 7), 100 \mu \mathrm{l}$ of $\mathrm{Na}_{2} \mathrm{~S}_{2} \mathrm{O}_{8}(0.1 \mathrm{M})$ and $375 \mu \mathrm{l}$ of water giving a final concentration of $80-100 \mu \mathrm{M} \mathrm{Mn}$,
$1 \mathrm{mM}\left[\mathrm{Ru}(\mathrm{bpy})_{3}\right]^{2+}, 10 \mathrm{mM} \mathrm{Na} \mathrm{S}_{2} \mathrm{O}_{8}$, and $50 \mathrm{mM}$ phosphate buffer. After argon purging and equilibration as above the cell was exposed to light (LEDs, $\lambda=470 \mathrm{~nm}, \sim 800 \mu \mathrm{E} \mathrm{m}^{-2} \mathrm{~s}^{-1}$ ).

The oxygen concentration in the solution was monitored in all experiments until it ceased to increase ( $c a$. 5-10 min). Oxygen evolution curves for each oxide sample and each oxidation method were measured at least twice.

\section{Mn(II) determination using EPR spectroscopy}

Mn(II) values were determined using EPR measurements at room temperature on a Bruker E500-ELEXSYS spectrometer with an ER 4102ST resonator. The supernatants obtained after centrifugation from the synthesis of the oxides were used as one set of samples. A calibration curve was prepared from samples of $\mathrm{MnCl}_{2}$ $(0.25-2.5 \mathrm{mM})$ in an acetonitrile/water mixture $(3: 1)$. A second set of samples was prepared from the mixture used in the Clark experiments. After centrifugation of the mixture the $\mathrm{Mn}$ (II) concentration was determined in the supernatant. The calibration curve was prepared using samples of $\mathrm{MnCl}_{2}(5-25 \mu \mathrm{M})$ in an acetonitrile/phosphate-buffer mixture $(3: 1,100 \mathrm{mM}$ phosphate buffer, $\mathrm{pH}$ 7). All samples were treated with $\mathrm{HNO}_{3}$ $\left(\left[\mathrm{HNO}_{3}\right]_{\text {final }}=0.18 \mathrm{M}\right)$ and filled into an EPR flat cell for the measurements.

\section{X-ray absorption spectroscopy}

The X-ray absorption spectroscopy (XAS) measurements were performed at the Helmholtz-Zentrum Berlin für Materialien und Energie (formerly BESSY II, Berlin) at the bending-magnet beamline KMC-1. The incident energy was set using a doublecrystal $\mathrm{Si}(111)$ monochromator with energy resolution of about $1 \mathrm{eV}$. The scanned energy region was between $6360 \mathrm{eV}$ and $7360 \mathrm{eV}$. The measurements were performed at $20 \mathrm{~K}$ in a cryostat (OxfordDanfysik) with a liquid-helium flow system. Sample 1a was measured as a concentrated solution ( $5 \mathrm{mM}$ in MeCN) and the other samples as pastes. To avoid photoreduction of the samples in the X-ray beam we performed the measurements at $20 \mathrm{~K}$ using a defocused beam and a new spot on the samples for each scan. A single scan of about 40 min duration was collected per irradiated sample spot, to exclude X-ray photoreduction. Data from 4-5 scans were averaged. Repeating two scans on the same spot did not show any indications of radiation damage. Thus we can rule out any significant influence of X-ray photoreduction on the presented data. Simultaneously with the sample, $\mathrm{KMnO}_{4}$ powder was measured as energy standard and for energy calibration the $\mathrm{KMnO}_{4}$ pre-edge peak position was set to $6543.3 \mathrm{eV}$. Further details are given in ref. 33 and in the ESI. $\dagger$

\section{Results and discussion}

The manganese oxide samples have been prepared by hydrolysis of two tetranuclear manganese complexes, $\left[\mathrm{Mn}^{\mathrm{III}}{ }_{4} \mathrm{O}_{2}(\mathrm{PhCOO})_{9}\right.$ $\left.\left(\mathrm{H}_{2} \mathrm{O}\right)\right] \mathrm{N}(n-\mathrm{Bu})_{4}(\mathbf{1 a})^{31}$ and $\left[\mathrm{Mn}^{\mathrm{III}}{ }_{4} \mathrm{O}_{2}(\mathrm{PhCOO})_{7}(\mathrm{PyCOO})_{2}\right] \mathrm{N}\left({ }^{n} \mathrm{Bu}\right)_{4}$ $(\mathbf{1 b})^{31}$ (Scheme 1). 1a have only benzoic acid ligands and $\mathbf{1 b}$ have both picolinic and benzoic acid ligands. Both complexes contain di- $\mu$-oxo bridged manganese ions and additional 


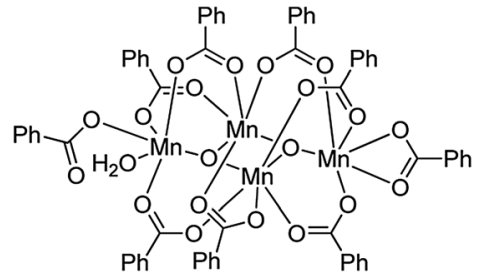

Scheme 1 Schematic structure of the anion of $\mathbf{1 a}$. The anion of $\mathbf{1 b}$ has two of the benzoic acid ligands, probably the two that are only coordinating a single $\mathrm{Mn}$ ion, and the water ligand replaced by two picolinic acid ligands.

carboxylate bridges. Structurally they resemble the $\mathrm{CaMn}_{4} \mathrm{O}_{5}$ core and the protein-derived ligands of the catalytic site of biological water oxidation.

Complexes 1a and $\mathbf{1 b}$ have been treated with an acetonitrilewater mixture yielding two manganese oxides, $2 \mathbf{a}$ and $\mathbf{2 b}$, respectively. A similar hydrolysis procedure has been reported by Skordilis and Pomonis for the preparation of a manganese oxide with a high surface area from a trinuclear manganese carboxylate complex. ${ }^{34}$ The oxygen evolution experiments (see below) have been carried out in aqueous potassium phosphate buffer ( $\mathrm{pH} 7$ ), where the phosphate ions work as a proton accepting base. ${ }^{35}$ It was also investigated as to how the presence of phosphate anions during the hydrolysis affects the hydrolysis products. For this $\mathbf{1 a}$ and $\mathbf{1 b}$ were treated with a mixture of acetonitrile and phosphate buffer, and hydrolysis yielded two manganese oxides, $\mathbf{3} \mathbf{a}$ and $\mathbf{3} \mathbf{b}$, respectively. Below we show that $\mathbf{3 a}$ and $\mathbf{3 b}$ differ dramatically from $\mathbf{2 a}$ and $\mathbf{2 b}$ both structurally and functionally.

The elemental analysis and IR spectra (Fig. 1) of $\mathbf{2 a}$ and $\mathbf{2 b}$ confirm formation of hydrated manganese oxides from the manganese complexes via hydrolysis in $\mathrm{CH}_{3} \mathrm{CN} / \mathrm{H}_{2} \mathrm{O}$ mixture.

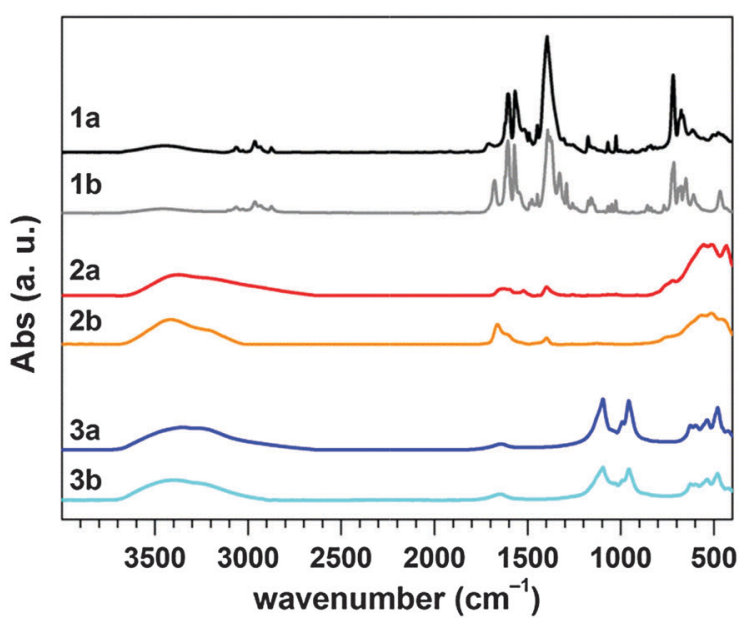

Fig. 1 IR spectra of starting manganese complexes (1a and $\mathbf{1} \mathbf{b})$ and prepared manganese oxides $(\mathbf{2} \mathbf{a}, \mathbf{2} \mathbf{b}, \mathbf{3} \mathbf{a}$, and $\mathbf{3} \mathbf{b})$. Sets of bands in the spectra of $\mathbf{l a}$ and $\mathbf{1 b}$ in the $1700-1200 \mathrm{~cm}^{-1}$ region correspond to the organic ligands in the complexes. The absence of those bands in the spectra of $\mathbf{2} \mathbf{a}, \mathbf{2} \mathbf{b}, \mathbf{3} \mathbf{a}$, and $\mathbf{3} \mathbf{b}$ indicates formation of inorganic solids after the hydrolysis procedure. The bands at $1100-950 \mathrm{~cm}^{-1}$ in the spectra of $3 \mathrm{a}$ and $3 \mathrm{~b}$ indicate the presence of phosphate anions in these samples.
The two IR spectra are very similar but not identical, likely due to differences in the level of hydration as indicated by the broad band at 3000-3500 $\mathrm{cm}^{-1}$. X-ray absorption spectroscopy (XAS) indicated an average $\mathrm{Mn}$ oxidation state of about +3.5 for $2 \mathrm{a}$ and $\mathbf{2 b}$ (Table 1 and Fig. 2, inset) and therefore the concentration of Mn(II) was also determined in the remaining supernatant after collecting the oxides. Mn(II) species, corresponding to $20 \pm 2 \%$ of all $\mathbf{M n}$ ions, are present in the supernatant for both $\mathbf{2 a}$ and $\mathbf{2 b}$. This indicates that a disproportionation reaction involving Mn(III) ions takes place simultaneously with the hydrolysis to form an amorphous mixed-valent Mn(III,Iv) oxide.

For the two oxides prepared in the presence of phosphate, the situation is quite different. Elemental analysis shows the presence of phosphorous in both $\mathbf{3 a}$ and $\mathbf{3 b}$. Phosphorous is present in $\mathbf{3 a}$ and $\mathbf{3 b}$ as phosphate-anions, as shown by the characteristic bands at $1100-950 \mathrm{~cm}^{-1}$ in the IR spectra ${ }^{36}$ of both $\mathbf{3 a}$ and $\mathbf{3 b}$ (Fig. 1). No Mn(II) was found in the supernatant, which implies that in the presence of aqueous phosphate buffer the Mn(III) carboxylate complexes are largely transformed into a Mn(III) oxophosphate. The average Mn oxidation state of the two oxides as determined using X-ray Absorption Near Edge Structure (XANES) is only slightly higher than +3 (Table 1 and Fig. 2, inset).

The four oxides were investigated as catalysts for water oxidation using photochemical and chemical oxidation. For the light-driven experiments, $\left[\mathrm{Ru}(\mathrm{bpy})_{3}\right]^{2+}$ was used as the photosensitizer, and persulfate $\left(\mathrm{S}_{2} \mathrm{O}_{8}{ }^{2-}\right)$ as the electron acceptor. For chemical oxidation, $\left[\mathrm{Ru}(\mathrm{bpy})_{3}\right]^{3+}$ (at about $\mathrm{pH}$ 7) and $\mathrm{Ce}(\mathrm{Iv})$ (at about $\mathrm{pH}$ 1) were used. The oxygen evolution traces (Fig. 3, and Fig. S1-S3, ESI $\dagger$ ) show clearly higher rates of water oxidation for $\mathbf{2} \mathbf{a}$ and $\mathbf{2 b}$ as compared to the phosphate containing oxides, $\mathbf{3 a}$ and $\mathbf{3 b}$, under all conditions (Table $\mathbf{1}$ ).

There is a small difference in the water oxidation activity between $\mathbf{2 a}$ and $\mathbf{2 b}$ most likely caused by differences in e.g. the water content of the oxides observed in the IR spectra (Fig. 1). These differences are not observed in the extended X-ray absorption fine-structure (EXAFS) spectra of $\mathbf{2 a}$ and $\mathbf{2 b}$ (see below). The same turnover frequencies (TOFs) were obtained in chemical and photochemical reactions with the tris-bipyridine ruthenium complex (Fig. S2, ESI, $\dagger$ Table 1). The activity in the photochemical reactions is decreasing over time. This phenomenon has been observed previously, e.g. using Co-oxides as catalysts ${ }^{37}$ and is most likely originating from a combination of degradation of the photosensitizer ${ }^{38}$ and depletion of the electron acceptor rather than from a major structural change of the Mn-oxide.

The oxygen evolution rate when using Ce(Iv) as an oxidant was three orders of magnitude lower than with $\left[\mathrm{Ru}(\mathrm{bpy})_{3}\right]^{3+}$ (Fig. S3, ESI, $\dagger$ Table 1). Cerium(Iv) is a more powerful oxidant than $\left[\mathrm{Ru}(\mathrm{bpy})_{3}\right]^{3+}$, but the low $\mathrm{pH}$ in the Ce(Iv) experiment as compared to the $\left[\mathrm{Ru}(\mathrm{bpy})_{3}\right]^{3+}$ experiments ( $\mathrm{pH} 1$ versus $\mathrm{pH} 7$ ) disfavours water oxidation strongly and may explain the comparatively low rates in the Ce(Iv) experiment. Comparison to the water oxidation activity of other manganese oxides ${ }^{13-16}$ reveals that $2 \mathrm{a}$ is orders of magnitude more active than any pure $\mathrm{Mn}$ (III) or $\mathrm{Mn}(\mathrm{Iv})$ oxide. It is more active than previously reported 
Table 1 Turnover frequencies ( $\mathrm{TOF}, \mathrm{mol} \mathrm{O}_{2} \mathrm{~S}^{-1}(\mathrm{~mol} \mathrm{Mn})^{-1}$ ) for oxygen evolution using three different oxidation agents and average $\mathrm{Mn}$ oxidation states estimated from XANES for $\mathbf{1 - 3}$ (plus literature values for further manganese oxides)

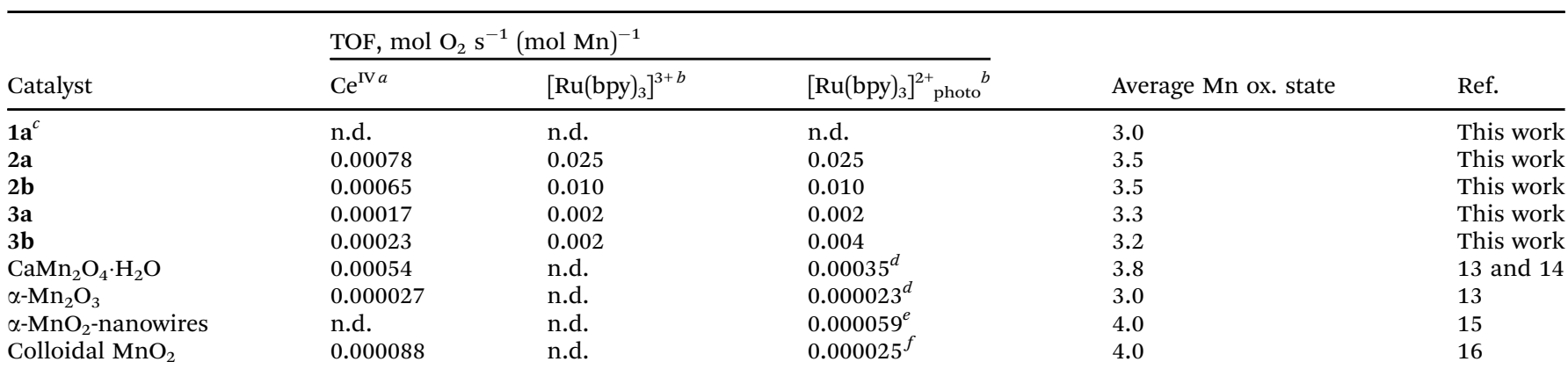

n.d. $=$ not determined. ${ }^{a} \mathrm{pH}<2 .^{b}$ Phosphate buffer ( $\left.\mathrm{pH} 7\right)$ used if nothing else stated. ${ }^{c}$ The activity of $\mathbf{1 a}$ (and $\mathbf{1 b}$ ) cannot be determined since hydrolysis to form $\mathbf{2 a}$ (and $\mathbf{2 b}$ respectively) is rapid in any solution containing water. ${ }^{d}$ An acetate buffer (pH 5) was used. ${ }^{e}$ No buffer was used. ${ }^{f}$ An acetate buffer ( $\left.\mathrm{pH} 4\right)$ was used.

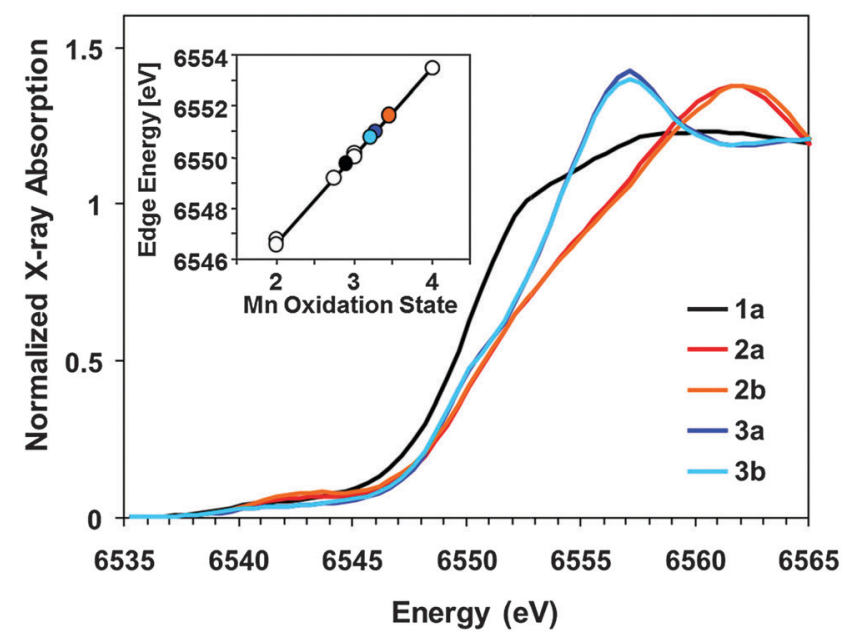

Fig. 2 XANES spectra of the investigated oxides recorded at the Mn K-edge. Inset: the average $\mathrm{Mn}$ oxidation state determined from the edge-position energy using a calibration line (circle symbol filled with the respective colour). For calibration, the XANES spectra of reference compounds with known oxidation state of manganese were employed $\left(\mathrm{Mn}^{\prime \prime} \mathrm{O}, \mathrm{Mn}^{\prime \prime} \mathrm{CO}_{3}\right.$, $\mathrm{Mn}_{2}{ }_{2} \mathrm{O}_{3}$ and $\beta-\mathrm{Mn}^{\mathrm{IV}} \mathrm{O}_{2}$, unfilled circles).

$\mathrm{CaMn}_{2} \mathrm{O}_{4} \cdot \mathrm{H}_{2} \mathrm{O}^{13}$ when using photochemical oxidation and at least as active with $\mathrm{Ce}(\mathrm{Iv})$ as the oxidant.

X-ray absorption spectroscopy at the Mn K-edge was employed to analyse the atomic structure of the four amorphous oxides. The recorded XANES ${ }^{39}$ spectra (Fig. 2) exhibit a low pre-edge intensity indicating that in all investigated oxides, the $\mathrm{Mn}$ ions are mostly six-coordinated and octahedral. The spectra also show a pronounced edge shape change between the initial molecular complex 1a and the oxides $2 \mathbf{a}$ and $3 \mathbf{a}$. The spectra of $\mathbf{2 b}$ and $\mathbf{3} \mathbf{b}$ have the same edge shape as the spectra of 2a and 3a, respectively. This is remarkable as they are formed from two different molecular complexes, $\mathbf{1 a}$ and $\mathbf{1 b}$, and confirms that the organic ligands in $\mathbf{1 a}$ and $\mathbf{1 b}$ are completely removed during hydrolysis. As judged from comparison of the XANES spectra, the structure of the resulting oxide depends on the presence or absence of phosphate ions in the acetonitrilewater mixture but not on the ligand system of the precursor complex.

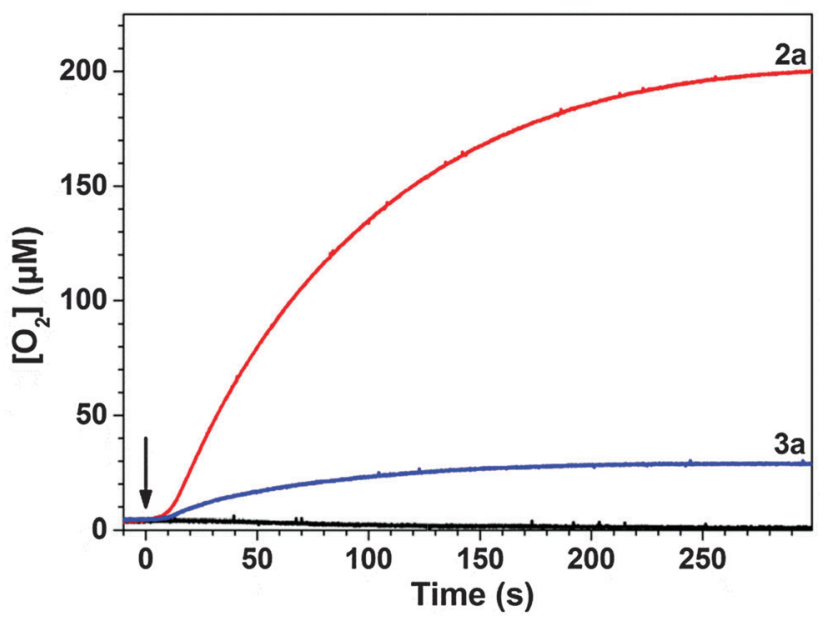

Fig. 3 Oxygen evolution traces showing the light-driven water oxidation catalysed by $\mathbf{2} \mathbf{a}$ (red, [Mn] $\sim 80 \mu \mathrm{M}$ ), $\mathbf{3 a}$ (blue, [Mn] $\sim 100 \mu \mathrm{M}$ ), or no catalyst (black) with $\left[\mathrm{Ru}(\mathrm{bpy})_{3}\right]^{2+}(1 \mathrm{mM})$ as photosensitizer and $\mathrm{S}_{2} \mathrm{O}_{8}{ }^{2-}(10 \mathrm{mM})$ as electron acceptor in $50 \mathrm{mM}$ phosphate buffer $(\mathrm{pH} 7)$. The arrow indicates the start of the illumination.

In $\mathbf{2 a}, \mathbf{2} \mathbf{b}, \mathbf{3} \mathbf{a}$, and $\mathbf{3 b}$, the edge-rise in the XANES spectra is found at a higher energy than in 1a. This indicates that Mn ions are oxidized above the +3 oxidation state. ${ }^{39}$ The Mn oxidation states of the catalytically active oxides were determined based on calibration with manganese compounds of known oxidation state (Fig. 2, inset). In $2 \mathbf{a}$ and $\mathbf{2 b}$ the average Mn oxidation state is +3.5 , while in $\mathbf{3 a}$ and $\mathbf{3 b}$, the $\mathrm{Mn}$ ions are only marginally more oxidized than in the initial molecular precursor (Table 1).

Information about the atomic structure of the oxides was obtained from the Mn K-edge EXAFS spectra. The EXAFS spectra of $\mathbf{2 a}$ and $\mathbf{2 b}$ are identical within the experimental noise level, and the same is true for the spectra of $\mathbf{3 a}$ and $\mathbf{3 b}$ (Fig. S4, ESI $\dagger$ ). The spectra from $2 \mathrm{a}$ and $3 \mathrm{a}$ are presented in Fig. 4 where visual inspection shows clear structural differences at the atomic level between the oxides formed in the presence or absence of phosphate. We note that typically each peak in the Fourier-transformed (FT) EXAFS corresponds to a 'vector' connecting the X-ray absorbing manganese atoms and 'backscattering atoms' of the first or a higher coordination sphere. ${ }^{39-41}$ 


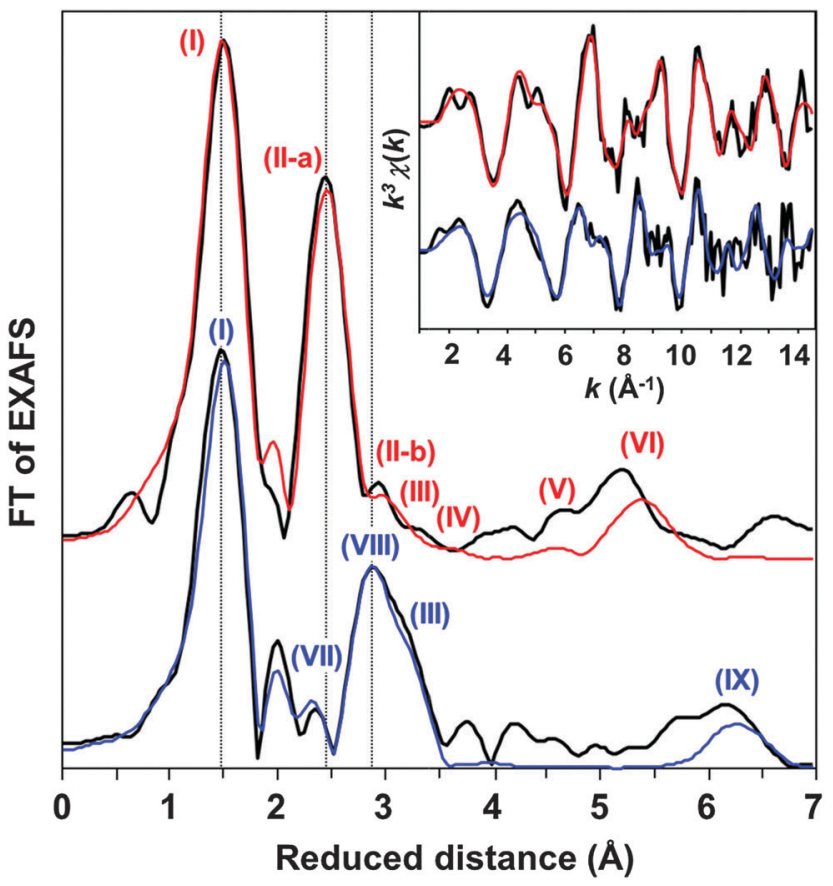

Fig. 4 Fourier-transformed EXAFS spectra of $\mathbf{2 a}$ (red) and $\mathbf{3 a}$ (blue). Inset: the original EXAFS spectra after transformation of the energy scale to a wavevector scale, before Fourier transformation $\left(k\right.$ in $\AA^{-1}, k^{3}$-weighted amplitudes). The experimental data is presented with thick lines and the simulated spectra with thinner coloured lines. The numbers next to the FT peaks correspond to the number of the coordination shell (Table 2) used to simulate the corresponding peak. The simulation parameters are presented in Table 2.

On the $x$-axis of the Fourier-transformed EXAFS spectra in Fig. 4 the 'reduced distance' is indicated, which is by about $0.4 \AA$ shorter than the real absorber-backscatter distance as obtainable by EXAFS simulations. The EXAFS amplitude decreases with $1 / R^{2}$ (where $R$ is the distance between the X-ray absorbing and the backscattering atoms). As a consequence, EXAFS oscillations are typically observed only for atoms within approximately $5 \AA$ of the absorbing atom. Longer distances, however, can be identified in periodic structures where multiple scattering by roughly collinearly arranged atoms results in increased amplitudes of the EXAFS oscillations. ${ }^{42}$ To obtain quantitative information about the number of backscattering atoms and their precise distance from the absorbing $\mathrm{Mn}$ ion, the experimental data were simulated according to the EXAFS equation ${ }^{40,41}$ (details given in the ESI $\dagger$ ); often a specific absorber-backscatter distance can be assigned to a distinct structural motif.

The simulation results for $\mathbf{2 a}$ are presented in Table 2 and all the considered structural motifs are schematically presented in Scheme 2. The first two shells in the simulation describe the oxygen ligands in the first manganese coordination sphere (I-a and I-b in Scheme 2); they correspond to peak-I in the FT of the EXAFS spectrum (Fig. 4). The total number of these ligands was fixed to six during the simulations, based on the low pre-edge intensity in the XANES spectra (Fig. 2). ${ }^{39}$ The Mn-O distances found in the simulation (Table 2) agree well with the presence $\mathrm{Mn}$ (III) and $\mathrm{Mn}$ (IV) ions ${ }^{43,44}$ and corroborate the mean Mn oxidation state of 3.5 estimated for this oxide from the XANES spectra.

Peak II in the EXAFS spectrum of 2a (Fig. 4) arises from di- $\mu_{3}$-oxo bridged manganese ions (II-a in Scheme 2). ${ }^{45}$ This bridging motif is characteristic of manganese oxide layers, which consist of edge-sharing $\mathrm{MnO}_{6}$ octahedra. The high EXAFS coordination number of 3.6 for these $\mathrm{Mn}-\mathrm{Mn}$ vectors indicates a relatively well ordered layered structure at the atomic level, although it also shows that the formed layers are imperfect (in a perfect manganese oxide layer, each X-ray absorbing

Table 2 Parameters obtained by simulation of the $k^{3}$-weighted EXAFS spectra. The simulated spectra correspond to the EXAFS spectra shown in the inset of Fig. 4. The shell labels for $\mathbf{2 a}$ and $\mathbf{3 a}$ correspond to the labels in Schemes 2 and 4 . The errors represent the $68 \%$ confidence interval of the respective fit parameter ( $N$, coordination number; $R$, absorber-backscatter distance; $\sigma$, Debye-Waller parameter). $R_{\mathrm{f}}$ error was calculated as described in ref. 39 and has values of $18.1 \%$ for oxide $\mathbf{2 a}$ and $23.8 \%$ for oxide $\mathbf{3 a}$

\begin{tabular}{|c|c|c|c|c|}
\hline Label & Assigned structural motif & $N$ & $R(\AA)$ & $\sigma^{a}(\AA)$ \\
\hline $\mathrm{I}-\mathrm{a}$ & $\mathrm{Mn}-\mathrm{O}$ & $4.84 \pm 0.18$ & $1.90 \pm 0.004$ & 0.059 \\
\hline $\mathrm{I}-\mathrm{b}$ & Mn-O* (elongated along the Jahn-Teller axis) & $1.16^{a}$ & $2.24 \pm 0.02$ & 0.059 \\
\hline $\mathrm{II}-\mathrm{b}$ & $\mathrm{Mn} \cdots \mathrm{Mn}\left(\mathrm{Mn}^{\mathrm{III}}\right.$ corner of distorted cubane) & $1.3 \pm 0.4$ & $3.10 \pm 0.01$ & 0.063 \\
\hline III & Mn $\cdots$ Mn (mono- $\mu$-oxo) & $0.6 \pm 0.5$ & $3.53 \pm 0.04$ & 0.063 \\
\hline IV & $\mathrm{Mn} \cdots \mathrm{Mn}\left(\mathrm{Mn}^{\mathrm{III}}\right.$ ion on top of layer vacancies) & $0.2 \pm 0.5$ & $3.79 \pm 0.16$ & 0.063 \\
\hline \multicolumn{5}{|c|}{ 3a (with phosphate) } \\
\hline $\mathrm{I}-\mathrm{a}$ & $\mathrm{Mn}-\mathrm{O}$ & $4.77 \pm 0.16$ & $1.94 \pm 0.005$ & 0.063 \\
\hline $\mathrm{I}-\mathrm{b}$ & Mn-O* (elongated along the Jahn-Teller axis) & $1.23^{a}$ & $2.20 \pm 0.02$ & 0.063 \\
\hline VII & Mn $\cdots$ Mn (di- $\mu$-oxo and phosphate bridge) & $0.3 \pm 0.2$ & $2.78 \pm 0.03$ & 0.063 \\
\hline VIII-a & $\mathrm{Mn} \cdots \mathrm{Mn}\left(\mathrm{Mn}-2 \mathrm{PO}_{4}{ }^{-}-\mathrm{Mn}\right)$ & $4.5 \pm 0.8$ & $3.18 \pm 0.02$ & 0.063 \\
\hline VIII-b & $\mathrm{Mn} \cdots \mathrm{P}$ & $5.2 \pm 1.2$ & $3.17 \pm 0.03$ & 0.063 \\
\hline
\end{tabular}

${ }^{a}$ The parameters were fixed (in case of $\sigma$ ), or calculated from another free parameter. ${ }^{b}$ Multiple-scattering was also taken into account for the simulation of this distance. 

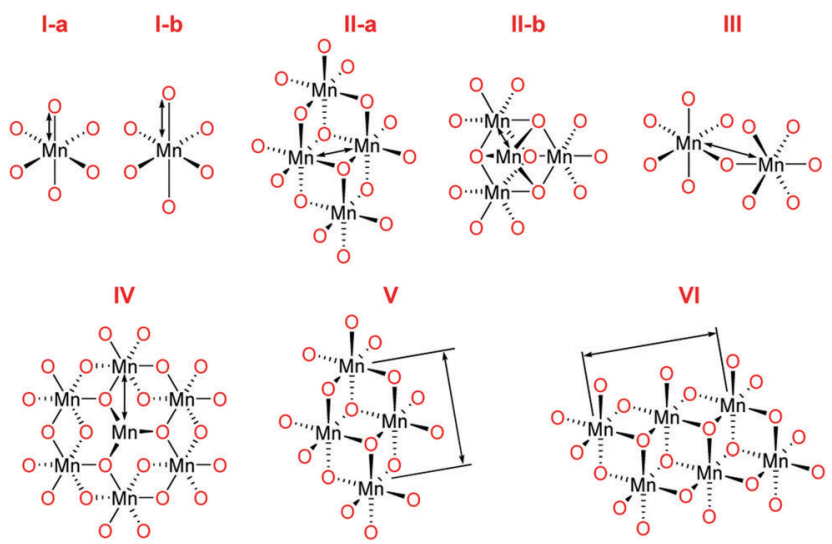

Scheme 2 Structural motifs considered in the EXAFS simulations of $\mathbf{2 a}$ The labels correspond to the labels in Table 2 and the peak labels in Fig. 4. Some of these motifs were also considered in the simulation of $3 a$ (see Table 2).

manganese should 'see' six neighbours at a distance of about $2.9 \AA$ Å). In a layered manganese oxide structure, we expect Mn-Mn distances equal to $2 \times \cos \left(30^{\circ}\right) \times 2.88=4.99 \AA(\mathrm{V}$ in Scheme 2) and $2 \times 2.88=5.76 \AA$ (VI in Scheme 2). These distances are indeed compatible with the presence of peak-V and peak-VI in the experimental spectrum (Fig. 4), but the corresponding EXAFS coordination numbers were relatively low, suggesting a defect-rich layer of $\mathrm{MnO}_{6}$ octahedra.

Typical defects are $\mathrm{Mn}(\mathrm{rv})$-vacancies in the layer resulting in negative charging of the defect site. This negative charge often is compensated by the adsorption of positive counter ions, specifically alkali or alkaline earth metals. ${ }^{46}$ The oxide $2 \mathbf{a}$ is prepared in the absence of counter ions (other than the $\mathrm{NBu}_{4}{ }^{+}$ ions present in 1a, which are not detectable in the IR spectrum of 2a). In the absence of redox-inert cations, $\mathrm{Mn}^{3+}$ ions most likely substitute for the alkali or alkaline earth cations in the $\mathrm{Mn}(\mathrm{III} / \mathrm{IV})$ oxide. The extra $\mathrm{Mn}^{3+}$ ions can bind at the layer fragment edges, resulting in the formation of distorted manganese-oxo cubanes $\left(\mathrm{Mn}_{4}(\mu-\mathrm{O})_{4}\right.$ motif, II-b in Scheme 2; one $\mathrm{Mn}$ ion may also be lacking, resulting in an incomplete $\mathrm{Mn}_{3}(\mu-\mathrm{O})_{4}$ cubane). $\mathrm{Mn}^{3+}$ ions can also be positioned on the top of $\mathrm{Mn}$ vacancies by binding to three $\mathrm{O}$ atoms from the layer (IV in Scheme 2). ${ }^{46}$ In the EXAFS spectrum of $2 \mathbf{a}$, the cubane motif is assignable to a small peak visible at the right side of peak-II-a; EXAFS simulations result a Mn-Mn distance of $3.10 \AA$ distance (Table 2). Manganese ions coordinated on top of a layer vacancy are assignable to peak-IV; simulations result in a Mn-Mn distance of close to 3.8 A. Similar binding positions of cations outside of the layers of edge-sharing $\mathrm{MnO}_{6}$ octahedra have been identified for $\mathrm{Ca}^{2+}$ or $\mathrm{Mn}^{3+}$ ions in catalytically active manganese oxides before. ${ }^{14}$ The same binding site for $\mathrm{Ca}^{2+}$ was also found in crystalline $\mathrm{Ca}_{2} \mathrm{Mn}_{3} \mathrm{O}_{8} \cdot{ }^{47}$ Mono- $\mu$-oxo bridged manganese ions (or corner-shared $\mathrm{MnO}_{6}$ octahedra, III in Scheme 2) correspond to a $3.5 \AA \mathrm{Mn}-\mathrm{Mn}$ distance in the EAXFS simulations. This bridging motif might be present in 2a (Peak III in Fig. 4), but the corresponding coordination number is very low, preventing the precise determination of the atomatom distance.

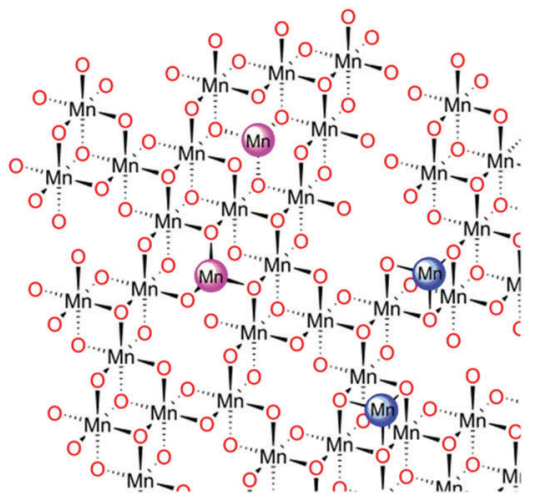

Scheme 3 Structural model for vacancy-rich manganese oxide layers in $\mathbf{2 a}$. Additional cations, in $\mathbf{2 a} \mathbf{~ M n}$ ions, are coordinated above or below the layer either capping manganese vacancies (magenta spheres) or forming complete or incomplete $\mathrm{Mn}_{4}(\mu-\mathrm{O})_{4}$ cubanes (blue spheres). The bridging and terminal oxygen atoms could be protonated or unprotonated.

In summary, the EXAFS analysis suggests that 2a, which is formed in the absence of phosphate, is a layered manganese oxide with a high number of defects in the form of missing Mn ions (vacancies). Additional Mn ions acting as counter ions to the negatively charged oxide layer are coordinated, most likely, above or below the layer. They cap Mn vacancies or form manganeseoxo cubanes. A fragment of such a manganese oxide layer is schematically shown in Scheme 3. Water molecules should also be present between layer fragments. Assuming that $\mathrm{Mn}^{2+}$ or $\mathrm{Mn}^{3+}$ ions are occupying the $\mathrm{Ca}^{2+}$ sites, 2a may closely resemble water-oxidizing calcium manganese oxides ${ }^{14,17}$ regarding the prevalent structural motifs.

The $\mathrm{Mn}$ ions in 3a are also 6-coordinated, but the average Mn oxidation state shows that the percentage of Mn(Iv) is lower than in 2a. This is reflected in the EXAFS spectrum (blue spectrum in Fig. 4) by the lower amplitude of the first FT peak (peak-I) and in the simulations (Table 2) by the slightly higher number of longer $\mathrm{Mn}-\mathrm{O}$ distances. The presence of the phosphate ions in the structure of 3a has to be taken into account in the simulation of $\mathrm{Mn}-\mathrm{Mn}$ distances and the additional structural motifs that were considered are presented in Scheme 4 . When a phosphate group is in a bridging position between two manganese ions, it either coordinates via the same oxygen atom ( $\mu$-phosphato- $\kappa^{2} \mathrm{O}, \mathrm{A}$ in Scheme 4$),{ }^{48}$ or via two different oxygen

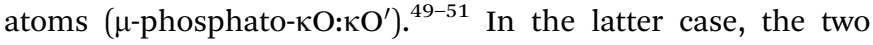

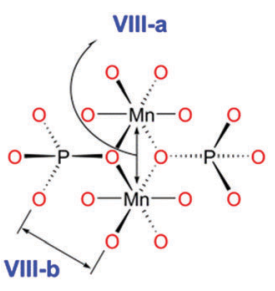

A

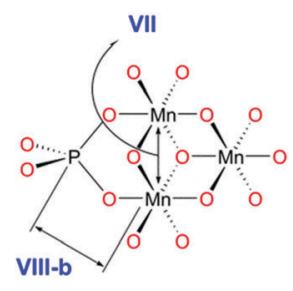

B

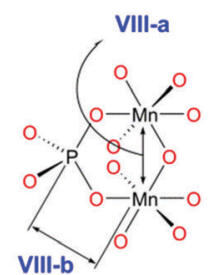

C
Scheme 4 Phosphate-containing structural motifs considered in the EXAFS simulations of $\mathbf{3 a}$. The labelled distances correspond to the labels in Table 2 and the peak labels in Fig. 4. 
manganese ions can have one or two additional oxygen bridges (e.g. B and $\mathrm{C}$ in Scheme 4, respectively). ${ }^{4,51,52}$ The resulting $\mathrm{Mn}-\mathrm{Mn}$ and $\mathrm{Mn}-\mathrm{P}$ distances will depend on the bridging motifs and on the oxidation state of manganese. ${ }^{53}$

In contrast to the situation in 2a, the short $\mathrm{Mn}-\mathrm{Mn}$ vector (Peak VII in Fig. 4) is of very low abundance in 3a and corresponds to a distance of only $2.78 \AA$ (versus $2.88 \AA$ in $2 \mathrm{a}$ ). A very short Mn-Mn distance is typical for molecular compounds, where in addition to di- $\mu_{2}$-oxo bridges the two manganese ions are connected with a carboxylate bridge (like for example in the $\mathrm{CaMn}_{4} \mathrm{O}_{5}$ complex in PSII ${ }^{54}$ or with an additional $\mu$-phosphato$\kappa \mathrm{O}: \mathrm{KO}^{\prime}$, which also results in a Mn-P distance of 3.0-3.1 $\AA^{49,51}$ For the latter type of bridging a di- $\mu_{2}$-oxo bridge with an additional phosphate bridge gave a $\mathrm{Mn}-\mathrm{Mn}$ distance of $2.70 \AA^{49}$ while in a cubane structure di- $\mu_{3}$-oxo bridges with additional phosphate bridges gave $\mathrm{Mn}-\mathrm{Mn}$ distances of 2.83-2.98 $\AA^{.51}$ The short $\mathrm{Mn}-\mathrm{Mn}$ vector in 2a could therefore correspond to a situation like that of motif $B$ in Scheme 4 with one $\mu_{2}$-oxo bridge, one $\mu_{3}$-oxo bridge and an additional $\mu$-phosphato$\kappa \mathrm{O}: \kappa \mathrm{O}^{\prime}$ bridge.

Peak-VIII in the spectrum of 3a may be assignable to $\mathrm{Mn}-\mathrm{P}$ distances from motifs A, B, or C (VIII-b in Scheme 4). Our simulations indicate a Mn-P distance of $3.17 \pm 0.03 \AA$, which is slightly longer than the distances of 3.01-3.14 $\AA$ reported in ref. 49 and 51 for structures similar to motif B. In a compound containing bridging phosphates with both motif $\mathrm{A}$ and motif $\mathrm{C}$, the Mn-P distances are 3.2-3.4 $\AA$ (ref. 48) and thus slightly longer than the distance determined for $\mathbf{3 a}$. In addition to the Mn-P distance, also Mn-Mn distances of 3.2-3.4 $\AA$ are present in the compound of ref. 48 , which is fully compatible with the EXAFS of 3a (VIII-a in Scheme 4, Table 2). Bermanite, a layered hydrated manganese phosphate, contains a motif with $\mathrm{Mn}$ (III)

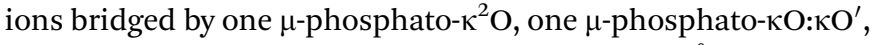
and one $\mu$-OH bridge. The Mn-Mn distances (3.1 $⿱$ A) and Mn-P distances (3.1-3.4 $\AA$ ) from this structure also compare well with our simulation results of $3 \mathrm{a}^{55}$

Peak III in the spectrum of $\mathbf{3 a}$ suggests the presence of a comparably high number of mono- $\mu$-oxo bridges between manganese ions. Limited long-range order is suggested by the presence of $\mathrm{Mn}-\mathrm{Mn}$ distances, which are longer than $6 \AA$ (Peak IX in Fig. 4). Further bridging motifs aside from the discussed ones cannot be excluded. The overall structure may be highly intricate, possibly exhibiting similarities with the multinuclear manganese-phosphate complexes reported by Yao et al..$^{52}$ and Wang et al..$^{48}$ or to bermanite. ${ }^{55}$

In summary, the EXAFS analysis suggests that 3a does not form layers or layer fragments of edge-sharing $\mathrm{MnO}_{6}$ octahedra. Aside from mono- $\mu$-oxo bridging (corner-sharing octahedra), bridging by phosphate ions may play a major structural role because the phosphates appear to serve as bridging ligands interconnecting two or more manganese ions (Scheme 4). This role of phosphate as a major structural determinant of the manganese oxides is surprising. In phosphate-containing cobalt-based $^{56,57}$ and nickel-based ${ }^{58}$ catalysts of water oxidation, extensive di- $\mu$-oxo bridging is observed, indicating the formation of (defect-rich) layers or layer-fragments of edge-sharing
$\mathrm{MO}_{6}$ octahedra. The phosphate ions are assumed to bind at the margin of layer fragments or be present in the interlayer space. $^{57}$

The rate of water oxidation in 3a is significantly lower than in 2a. We note that in these amorphous and highly hydrated oxides, the observed activity differences may be unrelated to the nanoscopic surface area. Investigations on binary manganese oxides did not reveal any correlation between surface area and water-oxidation activity. ${ }^{17}$ It has been concluded that water oxidation takes place within the bulk of the hydrated oxides at internal surfaces, specifically at the margins of metal-oxo fragments. ${ }^{53,54}$ Thus we assume that the observed activity differences relate to structural differences at the atomic level.

The two structurally distinct manganese oxides $(\mathbf{2} \mathbf{a} / \mathbf{2} \mathbf{b}$ versus $3 \mathbf{a} / \mathbf{3} \mathbf{b}$ ), facilitate discussion of structure-activity relations and provide insight into structural modifications caused by extensive phosphate ligation. In 2 , all structural key features are detected which we have been identified before as being of high relevance for catalytic activity of $\mathrm{Mn}$-based water oxidation catalysts: (i) absence of crystalline order, (ii) presence of both $\mathrm{Mn}(\mathrm{III})$ and $\mathrm{Mn}$ (IV) ions, (iii) extensive di- $\mu$-oxo bridging resulting in formation of fragmentary $\mathrm{MnO}_{2}$ oxide layers, (iv) water molecules likely located between oxide layers, (v) a high number of structural defects in the oxide layers which likely are associated with out-of-layer cations ${ }^{14,17,20,22,23,29,59}$ Similar structural key features have been identified in water oxidation catalysts based on other first row transition metals (Co and Ni). ${ }^{56-58}$ and in the biological catalyst consisting of a $\mathrm{CaMn}_{4}(\mu-\mathrm{O})_{5}$ oxide core bound to the proteins of PSII and facing a protein-internal water cluster ${ }^{7,8}$ with the $\mathrm{CaMn}_{4}(\mu-\mathrm{O})_{5}$-core-water-cluster interface presumably being of crucial functional importance (see, e.g., ref. 60).

In research conducted on biological water oxidation, a dual role of the di- $\mu$-oxo/hydroxo bridges has been proposed. ${ }^{54,61-63}$ On the one hand, four oxidizing equivalents need to be accumulated on the metal oxide cluster to oxidize two water molecules and form one dioxygen molecule. During this process, manganese oxidation could be coupled to deprotonation of a $\mu$-hydroxo bridge. This deprotonation prevents the increase of redox-potential for the next manganese oxidation event. On the other hand, a deprotonated $\mu$-oxo bridge could act as an internal proton-accepting base in the step of $\mathrm{O}-\mathrm{O}$ bond formation. ${ }^{54,61-63}$ The proposed dual role of the bridging oxygen atoms is possible only if the bridging oxygen atoms are bound to two transition metal ions $\left(\mu_{2}-\mathrm{O}\right)$ and not to three or even four $\left(\mu_{3}-\mathrm{O}\right.$ or $\left.\mu_{4}-\mathrm{O}\right){ }^{64}$ This means that in metal-oxide catalysts, it may be functionally decisive to have sufficiently 'unsaturated' oxo-bridges at structural defects where Mn ions are missing from the layer or at the periphery of manganeseoxide layer fragments. ${ }^{65}$ This hypothesis also explains that any well-ordered crystal structure would be catalytically largely inactive, as found before for relatively well ordered layered manganese oxides, ${ }^{20}$ for microcrystalline manganese oxides, ${ }^{14,59}$ and for microcrystalline calcium manganese oxides with structural similarities to the water-oxidizing cluster of PSII. ${ }^{14}$ 
In PSII as well as in inorganic metal oxides, a functional role of redox-inert cations $\left(\mathrm{Ca}^{2+}\right.$ or $\left.\mathrm{K}^{+}\right)$has been repeatedly proposed but so far not clearly identified. The phosphate-free oxide, 2, was prepared in the absence of other cations and thus Mn ions in a lower oxidation states may take the role of the redox-inert cations. This conjecture is in agreement with the EXAFS analysis presented above and has also been suggested to be the case for other manganese oxides synthesized in the absence of redox-inert ions. ${ }^{20,22,30}$ The possible functional role of the $\mathrm{K}^{+}$ ions from the buffer used for the water oxidation experiment with 2 cannot be completely excluded, although it is rather unlikely, taking into account the low catalytic activity of the layered manganese oxides containing $\mathrm{K}^{+}$as counter ions. ${ }^{17}$

The comparison between 2 and 3 also allows us to address the role of the phosphate ions in the catalytic process. The presence of a buffering system, often phosphate or borate containing buffers, is essential for the catalytic water oxidation activity in the neutral $\mathrm{pH}$ range. ${ }^{35}$ Phosphate ions cannot be further oxidized, which is an important feature of a buffer that should be used under highly oxidizing conditions. Phosphate ions have also been suggested to act as proton acceptors during water oxidation. ${ }^{66,67}$ Only under strongly alkaline conditions (pH 13-14), the catalytic activity of manganese oxide catalysts is observed in non-buffered $\mathrm{KOH}$ and $\mathrm{NaOH}$ solutions.

Although phosphate ions in the solution are clearly required for the water oxidation at neutral $\mathrm{pH}$, herein we show that their incorporation into a manganese oxide (3) strongly inhibits its catalytic activity. We attribute this loss of activity to the absence of a sufficient number of protonable di- $\mu$-oxo bridges. In 3 , the structure is instead dominated by manganese ions bridged by phosphate groups or mono- $\mu_{2}$-oxo bonds. Apparently these motifs cannot functionally substitute the lack of di- $\mu$-oxo bridging.

\section{Conclusions}

We have prepared two types of manganese oxide, 2 and 3, through hydrolysis of molecular Mn(III) precursors. Both are active as water oxidation catalysts, but 2 is the more active of the two oxides. The turnover frequencies (TOFs) of oxygen evolution for $\mathbf{2} \mathbf{a}$ and $\mathbf{2} \mathbf{b}$ were as high as, or higher than, the TOFs reported in the literature for other manganese and calcium/manganese oxides, both for photo-driven water oxidation and for chemical water oxidation using $\mathrm{Ce}(\mathrm{Iv})$.

During hydrolysis in acetonitrile-water, 2 is formed. This manganese oxide spontaneously forms the amorphous layer structure that has been found to be optimal for water oxidation activity. The structure is dominated by di- $\mu$-oxo bridged manganese ions with an average oxidation state of 3.5.

The inclusion of phosphate groups in a manganese oxide structure could potentially be beneficial by placing local proton acceptors close to the site of water oxidation. An adjustment of the conditions during hydrolysis of the Mn(III) precursor, including phosphate in the form of a buffered solution, led to the formation of 3 , a dramatically different manganese oxide: (i) the presence of phosphate in 3 resulted in a structure in which the important di- $\mu$-oxo bridged manganese ions are almost completely missing and the average oxidation state of manganese is close to +3 . (ii) Most likely the phosphate groups themselves are also acting as bridges between the manganese ions and therefore they are not capable of acting as proton acceptors. As a consequence of (i) and (ii), 3 is not as good a water oxidation catalyst as 2 , in spite of the presence of phosphate groups in the structure.

In this paper, a room temperature hydrolysis procedure was used to form the manganese oxides active as water oxidation catalysts. This type of procedure can be useful for applications where the oxide is used together with other components, such as dyes, that cannot sustain high temperatures. Another alternative is that the $\mathrm{Mn}$ (III) precursor could be adsorbed on a surface, e.g. on an electrode, and hydrolysed to form a catalytically active oxide coating in situ.

\section{Acknowledgements}

We thank M. Mertin and Dr F. Schäfers for technical support at beamline KMC-1 of the BESSY synchrotron operated by the Helmholtz Zentrum Berlin (HZB). DS, MFA, SS and AT acknowledge financial support from the Swedish Energy Agency and the Knut and Alice Wallenberg Foundation. HD and IZ gratefully acknowledge financial support from the Berlin cluster of excellence on Unifying Concepts in Catalysis (UniCat) and the Deutsche Forschungsgemeinschaft (SPP 1613).

\section{Notes and references}

1 N. S. Lewis and D. G. Nocera, Proc. Natl. Acad. Sci. U. S. A., 2006, 103, 15729-15735.

2 K. J. Young, L. A. Martini, R. L. Milot, R. C. Snoeberger, V. S. Batista, C. A. Schmuttenmaer, R. H. Crabtree and G. W. Brudvig, Coord. Chem. Rev., 2012, 256, 2503-2520.

3 A. Magnuson, M. Anderlund, O. Johansson, P. Lindblad, R. Lomoth, T. Polivka, S. Ott, K. Stensjö, S. Styring, V. Sundström and L. Hammarström, Acc. Chem. Res., 2009, 42, 1899-1909.

4 T. Faunce, S. Styring, M. R. Wasielewski, G. W. Brudvig, A. W. Rutherford, J. Messinger, A. F. Lee, C. L. Hill, H. deGroot, M. Fontecave, D. R. MacFarlane, B. Hankamer, D. G. Nocera, D. M. Tiede, H. Dau, W. Hillier, L. Wang and R. Amal, Energy Environ. Sci., 2013, 6, 1074.

5 A. Thapper, S. Styring, G. Saracco, A. W. Rutherford, B. Robert, A. Magnuson, W. Lubitz, A. Llobet, P. Kurz, A. Holzwarth, S. Fiechter, H. de Groot, S. Campagna, A. Braun, H. Bercegol and V. Artero, Green, 2013, 3, 43-57.

6 H. Dau and I. Zaharieva, Acc. Chem. Res., 2009, 42, 1861-1870.

7 H. Dau, I. Zaharieva and M. Haumann, Curr. Opin. Chem. Biol., 2012, 16, 3-10.

8 Y. Umena, K. Kawakami, J.-R. Shen and N. Kamiya, Nature, 2011, 473, 55-60. 
9 A. Sartorel, M. Bonchio, S. Campagna and F. Scandola, Chem. Soc. Rev., 2013, 42, 2262-2280.

10 I. Rivalta, G. W. Brudvig and V. S. Batista, Curr. Opin. Chem. Biol., 2012, 16, 11-18.

11 A. Harriman, M.-C. Richoux, P. A. Christensen, S. Mosseri and P. Neta, J. Chem. Soc., Faraday Trans. 1, 1987, 83, 3001-3014.

12 F. Jiao and H. Frei, Chem. Commun., 2010, 46, 2920-2922.

13 M. M. Najafpour, T. Ehrenberg, M. Wiechen and P. Kurz, Angew. Chem., 2010, 49, 2233-2237.

14 I. Zaharieva, M. M. Najafpour, M. Wiechen, M. Haumann, P. Kurz and H. Dau, Energy Environ. Sci., 2011, 4, 2400-2408.

15 V. B. Boppana and F. Jiao, Chem. Commun., 2011, 47, 8973-8975.

16 M. M. Najafpour, Dalton Trans., 2011, 40, 3805-3807.

17 M. Wiechen, I. Zaharieva, H. Dau and P. Kurz, Chem. Sci., 2012, 3, 2330-2339.

18 M. M. Najafpour and A. N. Moghaddam, Dalton Trans., 2012, 41, 10292-10297.

19 Y. Gorlin and T. F. Jaramillo, J. Am. Chem. Soc., 2010, 132, 13612-13614.

20 I. Zaharieva, P. Chernev, M. Risch, K. Klingan, M. Kohlhoff, A. Fischer and H. Dau, Energy Environ. Sci., 2012, 5, 7081-7089.

21 K. L. Pickrahn, S. W. Park, Y. Gorlin, H.-B.-R. Lee, T. F. Jaramillo and S. F. Bent, Adv. Energy Mater., 2012, 2, 1269-1277.

22 A. Bergmann, I. Zaharieva, H. Dau and P. Strasser, Energy Environ. Sci., 2013, 6, 2745.

23 B. A. Pinaud, Z. Chen, D. N. Abram and T. F. Jaramillo, J. Phys. Chem. C, 2011, 115, 11830-11838.

24 Y. Takahashi, A. Manceau, N. Geoffroy, M. A. Marcus and A. Usui, Geochim. Cosmochim. Acta, 2007, 71, 984-1008.

25 J. E. Post and D. R. Veblen, Am. Mineral., 1990, 75, 477-489.

26 T. Takashima, K. Hashimoto and R. Nakamura, J. Am. Chem. Soc., 2012, 134, 1519-1527.

27 T. Takashima, K. Hashimoto and R. Nakamura, J. Am. Chem. Soc., 2012, 134, 18153-18156.

28 R. Brimblecombe, A. Koo, G. C. Dismukes, G. F. Swiegers and L. Spiccia, J. Am. Chem. Soc., 2010, 132, 2892-2894.

29 R. K. Hocking, R. Brimblecombe, L. Y. Chang, A. Singh, M. H. Cheah, C. Glover, W. H. Casey and L. Spiccia, Nat. Chem., 2011, 3, 461-466.

30 A. Indra, P. W. Menezes, I. Zaharieva, E. Baktash, J. Pfrommer, M. Schwarze, H. Dau and M. Driess, Angew. Chem., 2013, 52, 13206-13210.

31 M. W. Wemple, H.-L. Tsai, S. Wang, J. P. Claude, W. E. Streib, J. C. Huffman, D. N. Hendrickson and G. Christou, Inorg. Chem., 1996, 35, 6437-6449.

32 V. Y. Shafirovich, N. K. Khannanov and A. E. Shilov, J. Inorg. Biochem., 1981, 15, 113-129.

33 M. Risch, D. Shevchenko, M. F. Anderlund, S. Styring, J. Heidkamp, K. M. Lange, A. Thapper and I. Zaharieva, Int. J. Hydrogen Energy, 2012, 37, 8878-8888.
34 C. S. Skordilis and P. J. Pomonis, J. Colloid Interface Sci., 1994, 166, 61-65.

35 K. Klingan, F. Ringleb, I. Zaharieva, J. Heidkamp, P. Chernev, D. Gonzales-Flores, M. Risch, A. Fischer and H. Dau, ChemSusChem, 2014, DOI: 10.1002/cssc.201301019.

36 F. A. Miller and C. H. Wilkins, Anal. Chem., 1952, 24, 1253-1294.

37 D. Shevchenko, M. F. Anderlund, A. Thapper and S. Styring, Energy Environ. Sci., 2011, 4, 1284-1287.

38 P. K. Ghosh, B. S. Brunschwig, M. Chou, C. Creutz and N. Sutin, J. Am. Chem. Soc., 1984, 106, 4772-4783.

39 H. Dau, P. Liebisch and M. Haumann, Anal. Bioanal. Chem., 2003, 376, 562-583.

40 J. E. Penner-Hahn, Coord. Chem. Rev., 1999, 190-192, 1101-1123.

41 J. J. Rehr and R. C. Albers, Rev. Mod. Phys., 2000, 72, 621-654.

42 J. E. Penner-Hahn, in Comprehensive Coordination Chemistry II, ed. J. A. McCleverty and T. J. Meyer, Elsevier Ltd., Oxford, UK, 2004, vol. 2, pp. 159-186.

43 R. W. G. Wyckoff, Crystal Structures, Interscience Publishers, New York, 2nd edn, 1963.

44 S. Geller, Acta Crystallogr., Sect. B: Struct. Sci., 1971, 27, 821-828.

45 M. Villalobos, B. Lanson, A. Manceau, B. Toner and G. Sposito, Am. Mineral., 2006, 91, 489-502.

46 T. G. Spiro, J. R. Bargar, G. Sposito and B. M. Tebo, Acc. Chem. Res., 2010, 43, 2-9.

47 G. B. Ansell, M. A. Modrick, J. M. Longo, K. R. Poeppelmeier and H. S. Horowitz, Acta Crystallogr., Sect. B: Struct. Sci., 1982, 38, 1795-1797.

48 M. Wang, C. Ma and C. Chen, Dalton Trans., 2008, 4612-4620.

49 J. E. Sarneski, M. Didiuk, H. H. Thorp, R. H. Crabtree, G. W. Brudvig, J. W. Faller and G. K. Schulte, Inorg. Chem., 1991, 30, 2833-2835.

50 K. Wieghardt, U. Bossek, B. Nuber, J. Weiss, S. Gehring and W. Haase, J. Chem. Soc., Chem. Commun., 1988, 1145-1146.

51 W. F. Ruettinger, D. M. Ho and G. C. Dismukes, Inorg. Chem., 1999, 38, 1036-1037.

52 H. C. Yao, Y. Z. Li, Y. Song, Y. S. Ma, L. M. Zheng and X. Q. Xin, Inorg. Chem., 2006, 45, 59-65.

53 S. Mukhopadhyay, S. K. Mandal, S. Bhaduri and W. H. Armstrong, Chem. Rev., 2004, 104, 3981-4026.

54 H. Dau, A. Grundmeier, P. Loja and M. Haumann, Philos. Trans. R. Soc., B, 2008, 363, 1237-1244.

55 A. R. Kampf and P. B. Moore, Am. Mineral., 1976, 61, 1241-1248.

56 M. Risch, V. Khare, I. Zaharieva, L. Gerencser, P. Chernev and H. Dau, J. Am. Chem. Soc., 2009, 131, 6936-6937.

57 M. W. Kanan, J. Yano, Y. Surendranath, M. Dinca, V. K. Yachandra and D. G. Nocera, J. Am. Chem. Soc., 2010, 132, 13692-13701.

58 M. Risch, K. Klingan, J. Heidkamp, D. Ehrenberg, P. Chernev, I. Zaharieva and H. Dau, Chem. Commun., 2011, 47, 11912-11914. 
59 E. Baktash, I. Zaharieva, M. Schroder, C. Goebel, H. Dau and A. Thomas, Dalton Trans., 2013, 42, 16920-16929.

60 A. Klauss, M. Haumann and H. Dau, Proc. Natl. Acad. Sci. U. S. A., 2012, 109, 16035-16040.

61 H. Dau, Biochim. Biophys. Acta, 2001, 1503, 24-39.

62 H. Dau and M. Haumann, Photosynth. Res., 2005, 84, 325-331.

63 H. Dau, C. Limberg, T. Reier, M. Risch, S. Roggan and P. Strasser, ChemCatChem, 2010, 2, 724-761.
64 G. Mattioli, M. Risch, M. A. Bonapasta, H. Dau and L. Guidoni, Phys. Chem. Chem. Phys., 2011, 13, 15437-15441. 65 M. Risch, K. Klingan, F. Ringleb, P. Chernev, I. Zaharieva, A. Fischer and H. Dau, ChemSusChem, 2012, 5, 542-549.

66 Y. Surendranath, M. Dinca and D. G. Nocera, J. Am. Chem. Soc., 2009, 131, 2615-2620.

67 M. W. Kanan, Y. Surendranath and D. G. Nocera, Chem. Soc. Rev., 2009, 38, 109-114. 